\title{
Design and Linkage Analysis of Theo Jansen Mechanism
}

\author{
Yash Punde ${ }^{1}$, Yugandhar Dhande ${ }^{2}$, Amit Chopde ${ }^{3}$, Sumedh Bagade ${ }^{4}$ \\ ${ }^{1,2,3,4}$ Student, Department of Mechanical, Vishwakarma Institute of Technology, \\ Maharashtra, India
}

\begin{abstract}
The Theo-Jansen linkage is an eleven-bar mechanism designed by Theo Jansen in his collection "Strandbeest." The mechanism is crank driven and mimics the motion of a leg. Its energy efficiency, and predeterminable foot motion show promise of applicability in legged robotics. Theo Jansen himself has demonstrated the usefulness of the mechanism through his "strandbeest" sculptures that utilize duplicates of the linkage whose cranks are turned by wind sails to supply a walking motion. The motion yielded is smooth flowing and comparatively agile. Because the linkage has been recently invented within a previous couple of decades, walking movement is currently the first application. Further investigation and optimization could cause more useful applications that need an identical output path when simplicity in design is important. The objective is to build up a new mechanical robotic walker using an eight-bar link mechanism. The system uses a robot that is capable of walking towards the object according to the remote-control input. A detailed analysis of the mechanism was done using the software. With the improvement and implementation of new technology, the cost of expenditure also increased and industries have had to set up roads for smoother movement of these wheel-based vehicles. The Theo-Jansen mechanism can extend an adaptive and controllable mechanism on irregular ground
\end{abstract}

Key Words: link, mechanism, theo-jansen, remote-controlled mechanism, all-terrain, linkage analysis.

\section{INTRODUCTION}

It is documented that animals can travel over rough terrain at speeds much greater than those possible with wheeled or tracked vehicles. Even a person's being, by "getting down on all fours" if necessary, can travel or climb over terrain which is impossible for a wheeled or self-propelled vehicle. It is therefore of considerable interest to find out what machines for land locomotion can do if they're designed to imitate nature. With this idea in mind, we started studying linkages and the comparative function of a set of linkages with certain degrees of freedom arrested. It turns out that numerous applications are possible if linkages are designed owing to the need.

\section{BACKGROUND}

History records many attempts to create machines that use legs in place of wheels. The following table lists early walking machines that have been identified during research.

1.In the year 200AD the china maker Zhunge Liang was designed a walking mechanism i.e Wooden ox, a transport vehicle used for military supply. Something it refers to the wheel barrow. 2..in the year 1770 the UK maker Richard Edge worth was designed a walking mechanism i.e A wooden horse with eight legs, capable of leaping over high walls. In spite of forty years work and hundreds of models, he was never able to make the idea work.

3. in this year 1968 the U.S.A maker General Electric was designed a walking mechanism i.e Walking truck. Capable of up to5 $\mathrm{mp}$ hand could climb over large obstacles.

4. in this year 1976 U.S.A maker Frank \& McGhee was designed a walking mechanism i.e "Phony Pony". First computer-controlled walking machine

Since the time of commercial revolution, mining has been an important and financial base of any running industry. With growing need of manufactured products, the necessity of raw material has increased substantially. Engineers have always tried to improvise and improve the utility of vehicles which help in transport of raw metals from the mining site to the transportation unit economically. With growing technology many improvements have been made in such vehicles (trucks, tippers, etc.). Some of those improvements include Conversion of tipper units from a single wheel drive (front/rear) to an all-wheel drive system.

1. Improvement of the suspension system.

2. Implementation of differential in vehicles to prevent skidding.

3. Development of advanced and heavy-duty tires.

\section{THEO JANSEN MECHANISM}

Model that can be actuated with only one motor, where input torque is driven to driving link. And, the driving link is constrained on origin of the Descartes coordinates. Also, the same Jansen link mechanism is utilized for constructing the other legs of the robot.

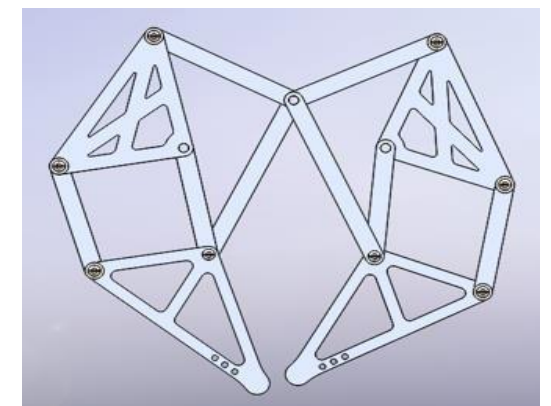

Fig 1. fore and back paw of Theo-Jansen mechanism 


\section{DESIGN}

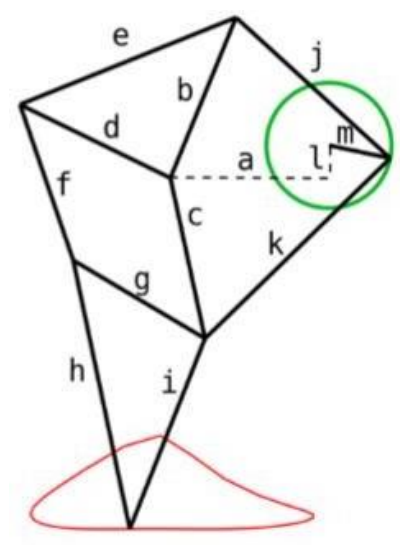

$a=38.0$

$\mathrm{b}=41.5$

$c=39.3$

$d=40.1$

$\mathrm{e}=55.8$

$f=39.4$

$g=36.7$

$\mathrm{h}=65.7$

$i=49.0$

$j=50.0$

$\mathrm{k}=61.9$

$l=7.8$

$\mathrm{m}=15 \cdot 0$

Fig 2 : Dimensions of various parts

The design of the entire prototype can be divided into two parts:

1) Manufacturing of mechanical parts like Crank and Crank shaft, pin joints, linkages, Fixture plates for motor mounting and shaft.

2) Driving of mechanism by electrical DC shunt motor on Bluetooth control using Arduino nano and motor driver L298n

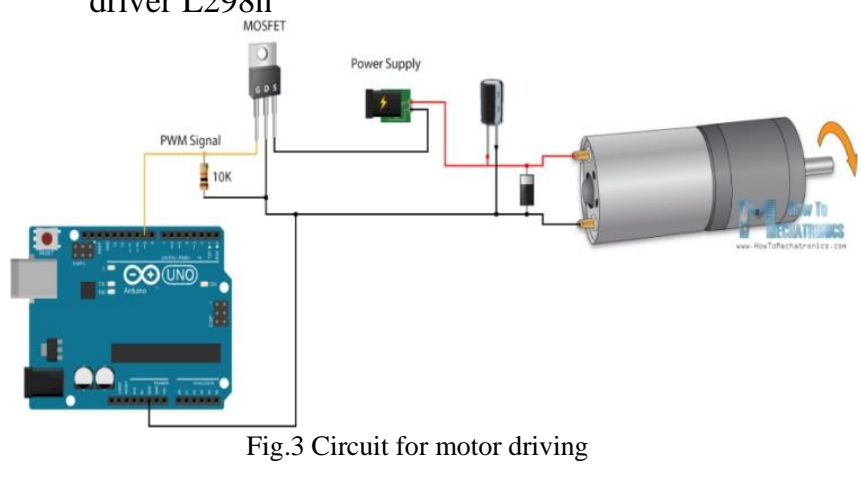

It is Kutzbach - Gruebler's equation for finding DOF

$$
M=6 n-\sum_{i=1}^{J}\left(6-f_{i}\right)=6(N-1-j)+\sum_{i=1}^{J} f_{i},
$$

Speed Control: Speed of mechanism are often controlled remotely using Arduino and Bluetooth controller from min rpm of motor to max rpm. this is often a really basic but necessary feature while operating the mechanism. to do this happen the concept of Pulse Width Modulation is realized. If the button is pressed if the figure, then the motor will start rotating and it'll be in motion until the button is pressed. This pressing is continuous and is represented within the first wave of figure. If, for a case, consider button is pressed for $8 \mathrm{~ms}$ and opened for $2 \mathrm{~ms}$ over a cycle of $10 \mathrm{~ms}$, during this case the motor won't experience the entire $9 \mathrm{~V}$ battery voltage because the button is pressed just for $8 \mathrm{~ms}$, therefore the RMS terminal voltage across the motor are going to be around $7 \mathrm{~V}$. thanks to this reduced RMS voltage the motor will rotate but at a reduced speed.

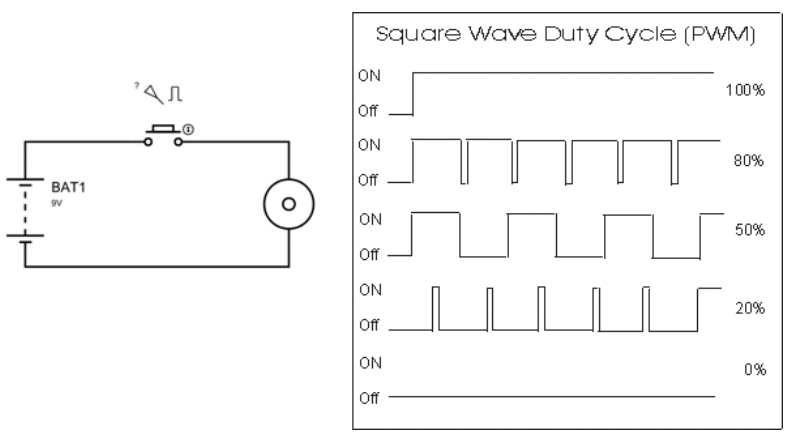

Fig.4 Speed control by PWM

Now the average turn on over a period of $10 \mathrm{~ms}=$ Turn ON time/ (Turn ON time + Turn OFF time), this is called duty cycle and is of $80 \%(8 /(8+2))$. By this technique all speeds in given range can be achieved by setting a desired value of power duty.

Turning: Vehicle are often steered left or right by reversing the direction of rotation of the other motor. The direction of steer is controlled by Bluetooth controller and arduino.This is achieved by employing a device called motor controller(IC 1298n). Motor driver uses an idea called $\mathrm{H}$ - bridge. For controlling the rotation direction, we just have to inverse the direction of the present flow through the motor, and therefore the most typical method of doing it, is by using an H-Bridge. An H-Bridge circuit contains four switching elements, transistors or MOSFETs, with the motor at the center forming an H-like configuration. By activating two particular switches at identical time we are able to change the direction of this flow, thus change the rotation direction of the motor

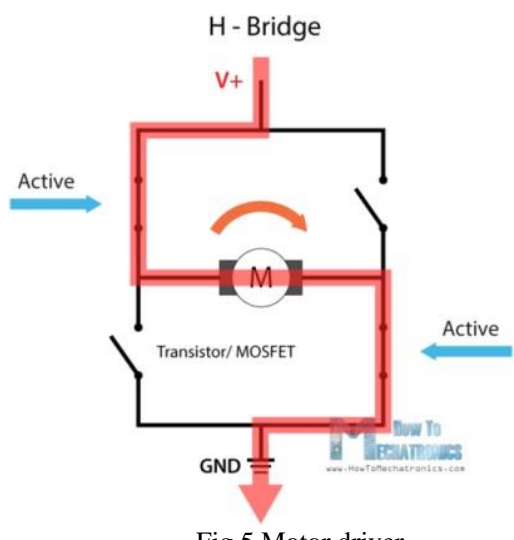

Fig.5 Motor driver

Thus, by controlling the direction of rotation of motor mechanism is steered. 


\section{CONSTRUCTION AND COMPONENTS}

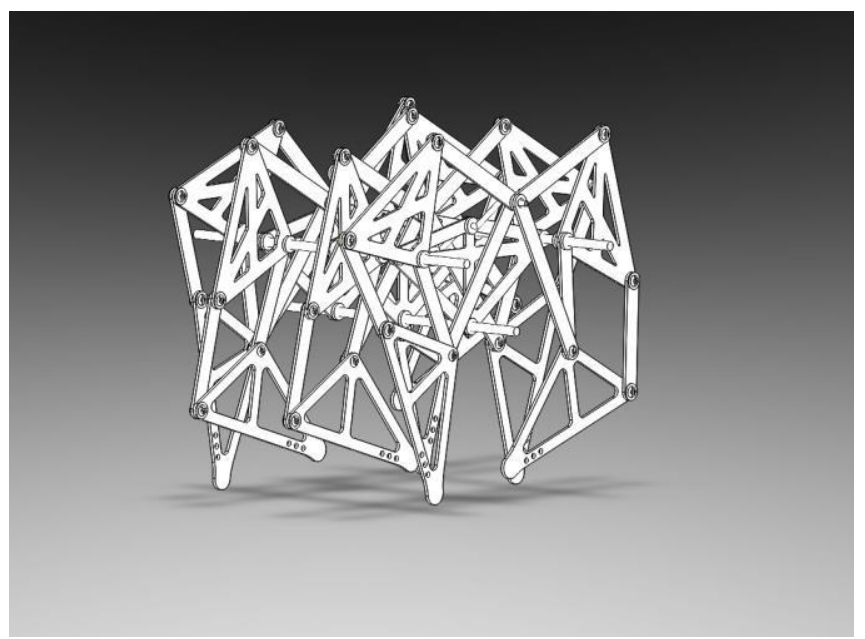

Fig-6: Assembly

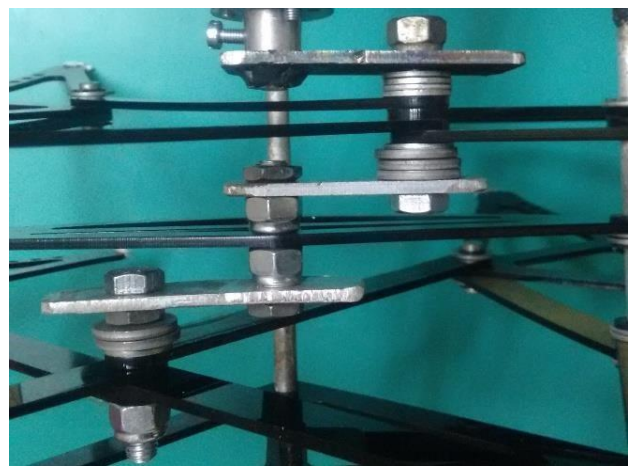

Fig-7: Crank and Crank shaft

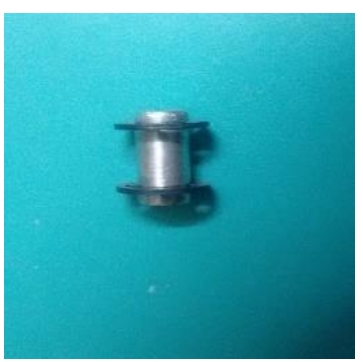

Fig 8- Pin joint

\section{ACTUAL MODEL}

The difference between the actual model and the CAD model is that actual model has some accuracy issues because of manufacturing and tolerances.

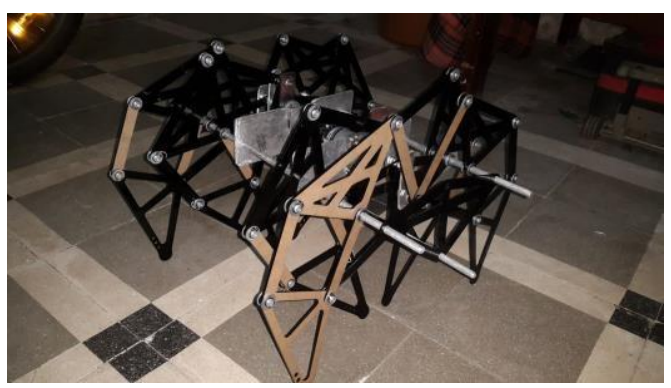

Fig-9: Actual Model

\section{MOTOR SELECTION:}

The basic criterion behind the selection of motor was torque output of motor for required specific rpm. According to the loading conditions of mechanism the maximum torque is required when the bot is transcending the step of maximum dimension. At this particular moment all the load from front is supposed to be carried by a leg which is in contact with the step. Now by equating the work done by motor to carry this load up to the height of step with work required we can calculate the value of torque required. Selected motor should have at least 5 to 6 times more torque than required to compensate for the fact that inertial and frictional forces were neglected during the calculations.

Table 1 motor selection calculations

\begin{tabular}{|c|c|c|}
\hline Length of crank & 35 & $\mathrm{~mm}$ \\
\hline Total mass & 3 & $\mathrm{~kg}$ \\
\hline Total weight & 29.43 & $\mathrm{~N}$ \\
\hline Weight on 1 leg & 14.715 & $\mathrm{~N}$ \\
\hline Maximum step length & 28 & $\mathrm{~mm}$ \\
\hline $\begin{array}{c}\text { Angle of rotation of } \\
\text { crank }\end{array}$ & 118 & $\mathrm{deg}$ \\
\hline $\begin{array}{c}\text { Angle of rotation of } \\
\text { crank }\end{array}$ & 2.059427778 & $\mathrm{rad}$ \\
\hline Work done & 412.02 & $\mathrm{~N}-\mathrm{mm}$ \\
\hline Torque required & 200.0652824 & $\mathrm{~N}-\mathrm{mm}$ \\
\hline Torque required & 0.200065282 & $\mathrm{~N}-\mathrm{m}$ \\
\hline Voltage & 12 & $\mathrm{volt}$ \\
\hline Current & 1.2 & $\mathrm{amp}$ \\
\hline Power & 14.4 & $\mathrm{watts}$ \\
\hline Torque & 3.1 & $\mathrm{~kg}-\mathrm{cm}$ \\
\hline $\begin{array}{c}\text { Torque (provided by } \\
\text { motor) }\end{array}$ & 0.30411 & $\mathrm{~N}-\mathrm{m}$ \\
\hline
\end{tabular}

\section{MODIFICATIONS:}

- Use of frictionless joints to reduce friction

- Use of metal links.

- Use of single piece crank.

- Use of high precision manufacturing techniques.

- Use of small capacity IC engines as a driver.

- Use of high precision servo motors.

- Use of proximity sensors.

- Various mounting owing to accessories. Use of GPS communication for increasing the range 10. RESULT AND ANALYSIS

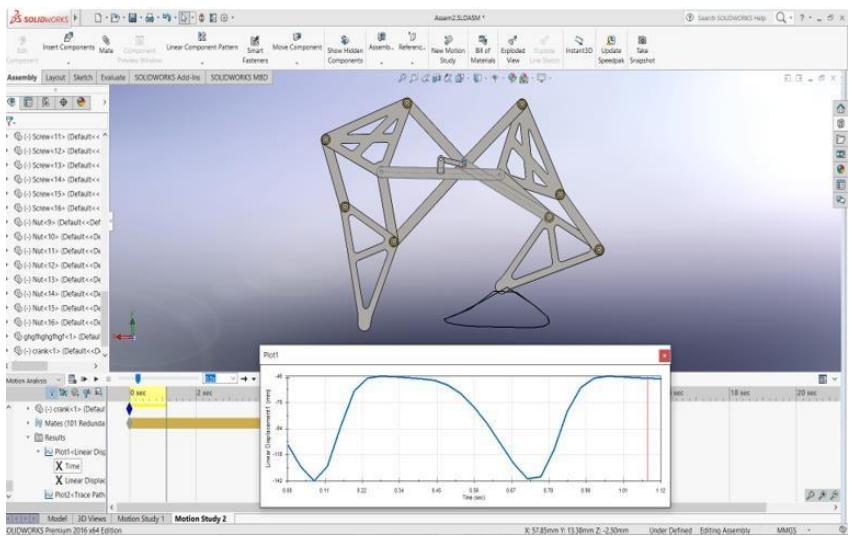

Fig-10: Path trajectory of paw linkage 
Which shows the symmetric trajectories of the toes of the Jansen linkage mechanism, it can be concluded that a stable walking behavior could be realized with ease given the similarity of the prior to the human walking gaits.

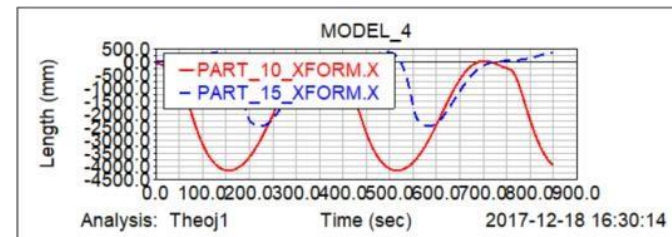

Fig 11 The time variation of $\mathrm{x}$-coordinate of the toes of the Jansen linkage mechanism

Which shows that the time variation of $\mathrm{x}$-coordinate between forepaw and back paw are not identical and there exists some differences. It represents that each toe moves with different speed consistently. As a result, it is expected for at least one leg to slip absolutely although both the legs tread the ground equally. It is commonly preferred to restrict toe slipping in walking robots regardless of biped or multi-legged platforms. However, the analysis results from above Fig. shows that a robot utilizing Jansen link mechanism can't walk without toe slipping. Therefore, toe slipping have to be allowed while the walking control system is designed for the platform.

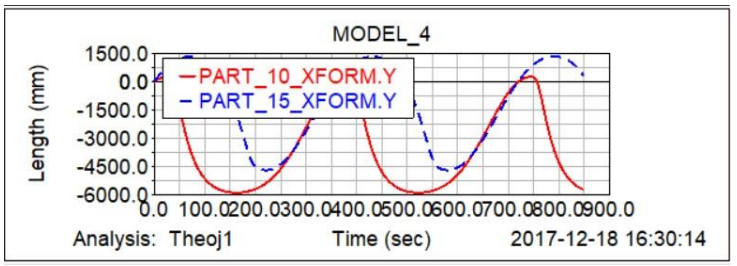

Fig 12 the time variation of $y$-coordinate of the toes of the Jansen linkage Mechanism

Which presents the time variation of y-coordinate of the toes of the Jansen linkage mechanism, it is obvious to find a $0.034 \mathrm{~m}$ difference between the lowest points of each leg. This observation concludes that a $0.03 \mathrm{~m}$ to $0.047 \mathrm{~m}$ motion is expected in a robot realized using 8-legged Jansen link mechanism. However, this up-and-down motion can be vanished by increasing the number of legs and decreasing the phase difference.

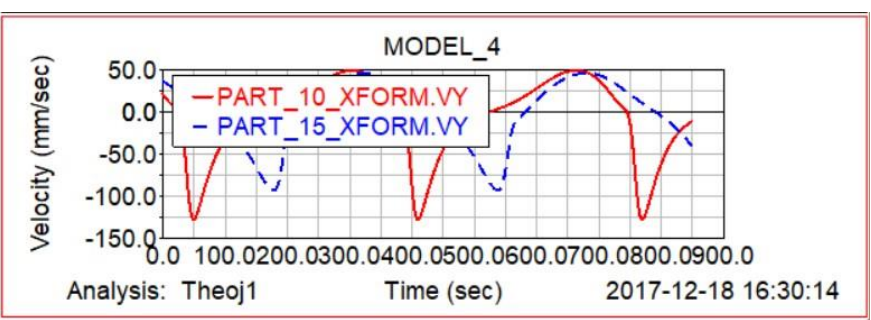

Fig 13 the time variation of $x$-velocities of the toes of the Jansen linkage mechanism

Which shows that there is phase difference between fore and back paw velocity linkages but with the same magnitude which possesses stability to the mechanism for forward motion and if velocities for fore and back paw are not same then the greater between the two will try to drag the remaining link and which will produce inefficiency and excessive unbalance to the mechanism.

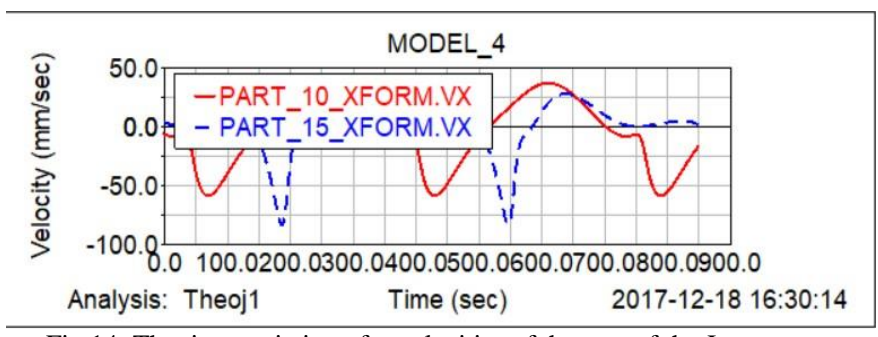

Fig 14: The time variation of y-velocities of the toes of the Jansen linkage mechanism

Which shows that for maximum velocity of fore paw velocity of back paw is zero and for maximum velocity of back paw velocity of fore paw is zero but maximum velocity variation directions are opposite in directions.

\section{CONCLUSIONS}

This research sets a basis for further investigation, optimization or extension of the Theo Jansen mechanism, our ongoing efforts in developing a reconfigurable Theo Jansen mechanism and any potential application of the same for real world scenarios.

Main problem faced with this mechanism was the bending of the leg linkages while turning, to avoid this problem high stiffness should be provided. Model developed can be further improved by reducing the friction present between the connections of links. Lateral rigidity can be increased by either increasing the thickness or width of the links. Prototype developed can be tested at various speeds and torques due to presence of the speed control system provided in electronic system. This enables us to use the prototype for various load handling capacities.

\section{ACKNOWLEDGEMENT}

The We would like to thank our MAJORPROJECT guide, Prof. DR.U.S. Chavan for his accurate suggestions, encouragement throughout the work that made us to present this report of this research work in an efficient manner. We would also like to thank Prof. Dr.M.B.Chaudhari, the Head of Mechanical Department, VIT, Pune for his guidance and support.We wish to express our deep gratitude to Prof. R.M. Jalnekar ,Director,VIT,Pune for providing the facilities of the institute. We would also like to thank to all our colleagues, friends, faculty members from mechanical department for creating a pleasant atmosphere during our work at VIT, Pune

\section{REFERENCES}

[1] Swadhin Patnaik, "Analysis Of Theo Jansen Mechanism (Strandbeest) And Its Comparative Advantages Over Wheel Based Mine Escavation System", IOSR Journal of Engineering (IOSRJEN),Vol. 05, Issue 07 (July. 2015).

[2] ThyssenKrupp Fördertechnik. (2005). Business Unit: Mining.

[3] Strandbeest: Theo Jansen from Art Futura, 2005. 
[4] Design (Constructional Characteristics) of Large Wheel Excavators. Journal of Mines, Metals, and Fuels, 34(4), 204213

[5] K. Rudy, L. Fawzy, Cleveland state university,1964

[6] S. Nansaia, M. Rajesh, M. Iwasea, "Dynamic Analysis and Modeling of Jansen Mechanism", International Conference On DESIGN AND MANUFACTURING, IConDM 2013 